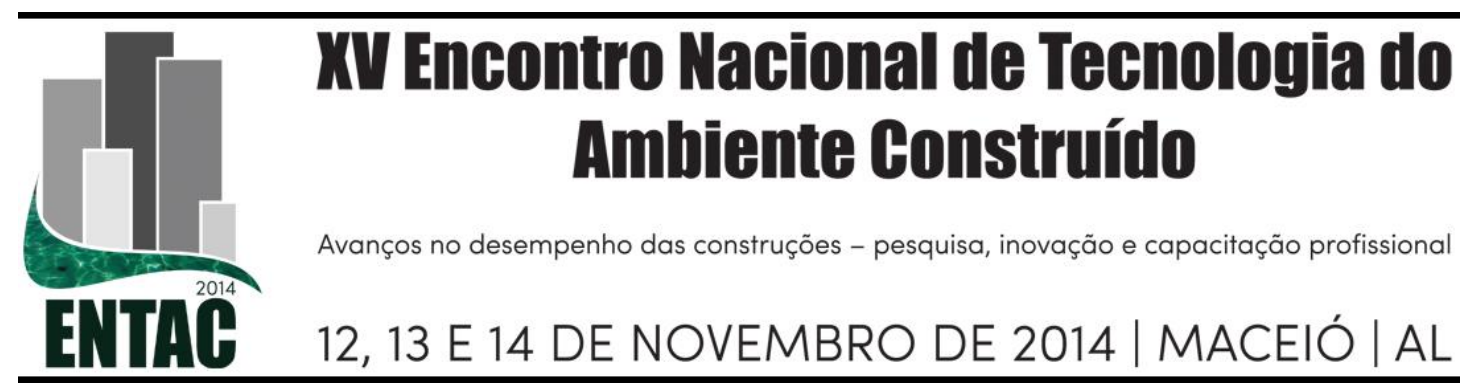

\title{
UTILIZAÇÃO DE PAINÉIS DE ALVENARIA NÃO CONFORMES NA CONSTRUÇÃO DE VESTIÁRIO EM CUIABÁ - MT
}

PORTO, Leonan Fonseca Sá (1); VALIN JR, Marcos de Oliveira (2)

(1) Tecnólogo em Controle de Obras pelo Instituto Federal de Ciência e Tecnologia de Mato Grosso - Campus Cuiabá (IFMT). E-mail: leonan.porto@gmail.com

(2) Prof. Esp. do Instituto Federal de Ciência e tecnologia de Mato Grosso - Campus Cuiabá (IFMT). E-mail: marcos.valin@cba.ifmt.edu.br

\begin{abstract}
RESUMO
$\mathrm{Na}$ busca pela produtividade na produção de edificações, tem-se verificado a necessidade de modernos sistemas construtivos com menor geração de resíduos, manutenabilidade e sustentabilidade. Então foi realizado um estudo de caso em um empreendimento de habitação de interesse social no município de Cuiabá - MT, que utiliza o sistema construtivo "JET CASA", com o objetivo analisar e discutir as dimensões da sustentabilidade no processo de produção do empreendimento com foco nas características intrínsecas ao sistema produtivo e na utilização de painéis, os não aprovados pelo controle de qualidade, porém sem comprometimento estrutural que podem ser utilizados para construções com fins sociais e não aqueles comerciais fazendo parte de um projeto de extensão do IFMT. A metodologia adotada constituiuse inicialmente pela construção do vestiário para campo de futebol no bairro próximo a obra, como alternativa social e sustentável para o reaproveitamento de painéis. Posteriormente foi analisado a qualidade e integridade do vestiário e em seguida foram aplicados 2 questionários semiestruturados, um para o residencial que já utiliza o sistema "JET CASA" e outro para o bairro onde foi construído o vestiário. Os resultados foram satisfatórios, pois referente ao questionário aplicado ao residencial (sistema "jet casa"), $70 \%$ das casas não presentaram nenhum tipo de patologia, $86 \%$ não apresentaram infiltração nas paredes e o mesmo porcentual, $86 \%$, não apresentaram problemas para a fixação nas paredes. Referente ao questionário aplicado ao bairro Itapajé, $92 \%$ dos moradores entendem que será muito bom a construção do vestiário junto ao campo de futebol para uso de lazer e incentivo ao esporte para a população. A pesquisa teve duas principais contribuições: a primeira foi social, com o oferecimento de uma estrutura física de lazer e a outra demonstrando a viabilidade técnica e sustentável da reutilização dos painéis.
\end{abstract}

Palavras-chave: Sustentabilidade, JET CASA, Painéis pré-fabricados de alvenaria.

\begin{abstract}
In the quest for productivity in buildings, there has been the need for modern construction with less waste, maintainability and sustainability systems. Then a case study was conducted in an enterprise of social housing in the city of Cuiabá-MT, which uses the constructive system "JET HOME", with the objective to analyze and discuss the dimensions of sustainability in the production process of the project focused intrinsic to the production system and the use of panels features, not approved by the quality control, but no structural change that can be used for buildings with social purposes and not commercial ones as part of an extension project IFMT. The methodology adopted was constituted initially by the construction of the locker room to the football field next quarter's work as a social and sustainable alternative to the reuse of panels. Was subsequently analyzed the quality and integrity of the locker room and then 2 semi-structured questionnaires, one for the home that already use "JET HOME" system and another for the neighborhood where it was built the locker room were applied. The results were satisfactory, since the questionnaire relating to the residential system ("Jet Home"), $70 \%$ of households do not presented any pathology, $86 \%$ had no seepage on the walls and the same percentage, $86 \%$, had no problems for fixation walls. Concerning the questionnaire to Itapaje neighborhood, $92 \%$ of residents believe that will be very good at building the field next to the football field for use of leisure and sports
\end{abstract}


incentive for the population. The research had two main contributions: the first was social, with the offer of a physical structure and other leisure demonstrating the technical viability and sustainable reuse of panels

Keywords: Sustainability, JET HOME and Prefabricated masonry panels.

\section{INTRODUÇÃO}

No ano de 2011, o déficit habitacional brasileiro era de aproximadamente 5,5 milhões de moradias (CAMARA, 2011). Na tentativa de suprir essa deficiência o Governo Federal, em parceria com os estados e municípios, criou em março de 2009, o Programa Minha Casa Minha Vida (PMCMV), gerido pelo Ministério das Cidades e operacionalizado pela Caixa Econômica Federal (CEF), com o objetivo de produzir unidades habitacionais para a venda às famílias que possuem renda familiar mensal de 0 a 3 salários mínimos.

A CEF possui vários sistemas construtivos homologados tecnicamente e que possuem a avaliação do IPT (Instituto de Pesquisa Tecnológicas) e do Instituto Falcão Bauer, comprovando a qualidade desses sistemas. Então, referente a industrialização da construção, Farah (1996) acredita que esta também constitui o caminho para enfrentar o enorme déficit habitacional urbano brasileiro. Contudo, para a produção em escala é necessário industrializar a construção de habitações, que de acordo com Trigo (2009), significa produzir de forma contínua e seriada, onde a construção é distribuída uniformemente por um período de tempo e exigindo noções de repetição e organização.

Com isso, a obra em estudo trata-se do Residencial Santa Terezinha, localizado próximo ao bairro Itapajé, na cidade de Cuiabá - MT. Esse residencial conterá aproximadamente 4.000 unidades habitacionais, todas com 2 quartos, mas com tipos de casas e metragem diferentes. $\mathrm{O}$ residencial foi dividido por setores, com datas de entrega diferentes, onde ao todo são 6 modelos de residências (A, B, C, D, E e F) e com metro quadrado de $36,76 \mathrm{~m}^{2}$ a $51,98 \mathrm{~m}^{2}$ de área construída. As casas do residencial em estudo foram construídas com a utilização do sistema construtivo "Jet Casa", painéis pré-fabricado de alvenaria, por ser um método rápido e econômico e o vestiário, para campo de futebol foi construído no bairro próximo a esse residencial como alternativa social e sustentável para minimizar os impactos causados durante a execução da obra.

O sistema "Jet Casa" é um método que consiste na construção de paredes, lajes e fundação pré-fabricada para casas térreas isoladas ou geminadas e sobrados isolados ou geminados. É constituído de paredes estruturais de painéis pré-fabricados unindo concreto armado e blocos cerâmicos já incluso as instalações elétricas e hidráulicas (PEPPE \& BRANDT, 2009).

Esse trabalho tem por objetivo verificar se o sistema construtivo "Jet Casa" atende aos princípios de sustentabilidade com a reutilização dos painéis reprovados, para fins comerciais, na construção de um vestiário para campo de futebol em um bairro de Cuiabá. Analisando assim os critérios de reprovação dos painéis, por parte da empresa construtora, as patologias encontradas na produção e montagem das peças préfabricadas. E ainda verificar a satisfação dos moradores do residencial, construído com o sistema "Jet Casa" e também a satisfação dos moradores do bairro Itapajé quanto a construção do vestiário.

Foram aplicados questionários para as devidas avaliações da estrutura das casas construídas pelo sistema "Jet Casa" e para a satisfação dos moradores do bairro onde foi construído o vestiário. 
Após a coleta dos questionários, os resultados foram tabulados para identificar o nível de satisfação dos moradores das residências com sistema "Jet Casa" e também dos moradores do entorno com a construção do vestiário.

\section{BREVE HISTÓRICO DA HABITAÇÃO NO PAÍS}

Conforme Lorenzetti (2001, p.4), assim como a vestimenta e a alimentação, a moradia pode ser também considerada uma necessidade humana básica. Então a habitação deve fazer parte das ações nacionais e internacionais por proporcionar o bem-estar físico, social, psicológico e econômico da pessoa humana (AGENDA HABITAT, 1997, p.2).

O surgimento da questão habitacional no país se deu pela decadência da economia cafeeira no Vale do Paraíba no que sucedeu-se o surto manufatureiro-industrial a partir de 1870 (COELHO, 2002). Nesse mesmo pensamento, Coelho (2002), diz que o aumento do fluxo de imigrantes e escravos libertos e ainda a redução da mortalidade, devido as políticas de saneamento, agravou a demanda por habitação com o aumento da população nas cidades.

Então Ferreira \& Uemura (2009) salientam que a dramática situação da moradia que assola as cidades brasileiras não deva ser encarada como uma questão ingênua, ou seja, resultado natural do crescimento urbano. E sim porque tais problemáticas possuem raízes na forma com que se organizou nossas cidades, onde constitui um Estado patrimonialista com o controle absoluto das elites dominantes sob o acesso à terra, rural e urbanas.

O surgimento das favelas e cortiços no Brasil, se deu com a população pobre sendo excluída do mercado imobiliário regular, pois no país não havia intervenção do Estado na área social e a forma de provisão habitacional era por meio dos mercados de aluguéis o que restou aos pobres, como alternativa, essas "cidades ilegais" (ABRAMO, 2002).

Nessa ótica, Bonduki (1998) explica que a habitação das classes populares ocorreu por meio da produção privada das vilas operárias ou de moradias de aluguel, onde as vilas tiveram incentivo do poder público por meio de isenções fiscais, sendo considerada uma solução de disciplinamento e higienização das massas. Contudo, só tinham acesso à essas moradias de melhor qualidade, embora populares, operários qualificados, funcionários públicos e comerciantes. Por isso os cortiços, de qualidade ainda pior, representou a única forma de acesso a moradia pela maioria da população.

Então, somente a partir de 1930 na Era Vargas, o governo começou a investir em infraestrutura urbana e regional, com o objetivo de impulsionar o desenvolvimento industrial, onde se deu a construção dos primeiros conjuntos habitacionais, mas que em sua grande maioria destinada à uma determinada categoria profissional (MARICATO, 1997).

Houveram melhoras na qualidade de vida urbana nas maiores cidades do país nos últimos anos em razão da forte inversão em infraestrutura e serviços, que por muitas vezes foi possibilitada por empréstimos de instituições internacionais obtidos pelo governo (BRASIL, 2011). Mas este cenário ainda possui muitos desafios se analisado o acesso universal dos direitos sociais, entre eles o direito a moradia (BRASIL, 2011).

Conforme pesquisa do IPEA (2013) o déficit habitacional é um dos problemas no nosso país, mas que diminui a cada ano. De 2007 a 2012 houve a criação de 350 mil novas residências o que representou um aumento de $8,53 \%$. A pesquisa ainda informa que o Déficit Habitacional é um indicador que auxilia a sociedade e a gestão pública a 
visualizar a necessidade de reposição do estoque de moradias e a partir disso o desenvolvimento das devidas políticas públicas.

\section{A SUSTENTABILIDADE}

A geração de resíduos da construção é difusa e cerca de $70 \%$ é proveniente do pequeno gerador com reformas, pequenas obras e demolição onde, na maioria das vezes, são coletados pelo serviço de limpeza urbano (GOVERNO DO ESTADO DE SÃO PAULO, 2012).

Diante dessa problemática, para organizar e atender as necessidades de uma gestão dos resíduos, a Resolução CONAMA 307 apresenta um modelo de gestão onde responsabilidades são definidas para os agentes envolvidos na geração dos resíduos: geradores, transportadores, áreas de destinação e municípios, onde este último, deve elaborar o plano municipal e estabelecer diretrizes, critérios e procedimentos aos agentes envolvidos (GOVERNO DO ESTADO DE SÃO PAULO, 2012).

Para isso a Resolução CONAMA 307 define os resíduos da construção civil como sendo da Classe A, ou seja, aqueles advindos das construções, reformas, reparos e demolições de obras de construção civil e também os resultantes da preparação e escavação de terrenos, como: tijolos, blocos cerâmicos, concreto em geral, solo, rocha, madeira, forro, argamassa, telha, pavimento asfáltico, vidros, plásticos, tubulações, fiação elétrica, etc.

Podemos encontrar definições para sustentabilidade, tais como:

As atividades humanas relacionadas à extração dos recursos naturais devem ser consideradas se puderem ser mantidas ao logo do tempo. Essa extração está relacionada aos recursos naturais que se mantêm efetivamente constantes ao longo do processo de extração (HOWE, 1979).

Já Silva \& Moraes (2011), pensam que:

[...] sustentabilidade representa promover a exploração de áreas ou o uso de recursos planetários (naturais ou não) de forma a prejudicar o menos possível o equilíbrio entre o meio ambiente e as comunidades humanas e toda a biosfera que dele dependem para existir.

Em meio a essas definições da sustentabilidade o Tratado de Educação Ambiental (1992) salienta que:

Ela estimula a formação de sociedades socialmente justas e ecologicamente equilibradas, que conservam entre si relação de interdependência e diversidade. Isto requer responsabilidade individual e coletiva em nível local, nacional e planetário.

Nessa mesma linha de raciocínio, Silva e Shimbo (2006), classificam a sustentabilidade em 5 dimensões: a) Dimensão Ambiental: minimização dos impactos urbanos.; b) Dimensão Social: igualdade de acesso a bens, equipamentos e serviços públicos e qualidade no espaço de lazer, transporte, etc.; c) Dimensão Econômica: distribuição de riqueza pela geração de trabalho e renda.; d) Dimensão Cultural: promoção da identidade e diversidade cultural em suas formas de expressão, e; e) Dimensão Política: espaços para tomada de decisões e participação democrática.

Mesmo que haja a conceituação da literatura a respeito da sustentabilidade, a maioria das grandes cidades fica em dúvida entre proporcionar uma qualidade de vida melhor à 
sua população e conservar o meio ambiente. Nesse dilema as construtoras desenvolveram novas formas de construir seus empreendimentos com pensamento na conservação dos recursos naturais, como energia e água e ainda na redução das emissões de poluentes advindos dos imóveis (ATITUDESSUSTENTÁVEIS.COM.BR, 2013).

Referente a construção, os impactos dela causados ao meio ambiente são vários desde a extração das matérias-primas até o término da vida útil dos produtos construídos, envolvendo a reutilização, reciclagem ou descarte dos mesmos (GUIA DE BOAS PRÁTICAS EM SUSTENTABILIDADE, 2012).

Contudo, o caminho a percorrer rumo aos empreendimentos totalmente sustentáveis e ecologicamente corretos ainda é longo, até por que o imenso volume de resíduos e descartes de materiais tóxicos e poluentes do meio ambiente é oriundo da construção civil (ATITUDESSUSTENTÁVEIS.COM.BR, 2013).

Com isso, a prática de ações de sustentabilidade pode garantir um mundo nas condições necessárias para o desenvolvimento das várias formas de vida, incluindo a vida humana, a médio e longo prazo. Garantindo, dessa forma, estoque de recursos naturais necessários para as próximas gerações e a qualidade de vida (SUAPESQUISA.COM, 2013).

Com o conceito de sustentabilidade sendo frequentemente abordado em várias esferas na construção civil, o PBQP-H, passou por revisão e em 2012 entrou em vigor que as empresas construtoras do subsetor, obras de edificações, são obrigadas a implementar e manter indicadores voltados a Sustentabilidade nos canteiros de obras, se referindo minimamente aos: Indicadores de geração de resíduos, Indicadores de Consumo de Água e de Energia (PROGRAMA BRASILEIRO DE QUALIDADE E PRODUÇÃO DO HABITAT - PBQP-H, 2012).

\section{O SISTEMA CONSTRUTIVO "JET CASA"}

A revista Techne (2005) expõe que os fabricantes foram obrigados a atualizarem produtos e tornar os preços mais competitivos, pois com a abertura do mercado internacional os produtos importados tinham melhor qualidade que os nacionais.

Nesse sentido Peppe \& Brandt (2009) informam que o sistema construtivo "Jet Casa" surgiu com a intenção de seguir o tempo de finalização da obra, reduzir desperdícios, onde é executado com maior planejamento, possibilitando um maior controle de qualidade e o respeito ao meio ambiente.

O sistema "Jet Casa" envolve um método de fabricação de painéis e que são usados para diversos tipos de projetos habitacionais, sendo estruturados e autoportantes (JETCASA, 2013).

Então conforme o site JetCasa.com.br (2013) todo o processo faz parte de uma moderna linha de produção, composta por uma fábrica contendo trilhos, pórticos, fôrmas e moldes, com a oferta de redução dos custos, prazos da obra, diminuição dos desperdícios de materiais e facilidade no planejamento e controle.

Para entendermos melhor os sistemas construtivos, alguns são definidos como elementos pré-fabricado ou pré-moldado, onde o primeiro é realizado industrialmente sob condições rigorosas de controle de qualidade e o segundo com um controle menos rigoroso. Mas são incomuns, pois são produzidos fora do local de utilização definitiva (NBR 9062, 1985). 
Esse sistema "Jet Casa" é direcionado à produção industrializada, unindo concreto armado e blocos cerâmicos criando elementos como paredes, lajes, blocos e fundação pré-fabricados que normalmente são destinados a unidades habitacionais. A união dos painéis pré-fabricados formam as paredes que receberão os oitões e lajes e as tubulações elétricas e hidráulicas são embutidas nos próprios painéis. Essa ligação entre os painéis é mecânica e realizada por meio de soldagem de barras de aço estrategicamente posicionadas nos painéis pré-fabricados (PEPPE \& BRANDT, 2009).

Um padrão é estipulado ao sistema "Jet Casa" em relação ao comprimento, altura e espessura dos painéis, sendo 3,50 $\mathrm{m}$ de comprimento, altura de acordo com o pé direito das edificações e espessura de $11 \mathrm{~cm}$ ou $14 \mathrm{~cm}$ (paredes geminadas) levando em conta 1 cm para cada camada, interna e externa (SINAT, 2011).

\section{MÉTODO}

Este trabalho tem como tipo de pesquisa a de campo, na área da construção civil, onde seu objetivo consiste na pesquisa exploratória cuja natureza é quanti-qualitativa.

Para a realização dos serviços (fabricação e montagem dos painéis) a empresa segue a IT (Instrução de Trabalho) criada pela mesma através de normas e do conceito do próprio sistema "Jet Casa" e para a caracterização dos painéis aprovados e reprovados, o método utilizado foi o acompanhamento das Fichas de Verificação de Serviços (FVS) da fábrica, que informa o tipo e o local da patologia que levou ao descarte do painel, como forma de rastreabilidade.

A construção do vestiário foi realizada por equipe especializada na montagem, a mesma que atua no residencial, com a utilização de caminhão guindauto (munk) para o transporte dos painéis onde a junção dos painéis foi realizada por soldagem como padroniza o próprio sistema "Jet Casa". O vestiário foi construído com painéis que foram fabricados em Julho e Agosto de 2013 e ficaram estocados, em local apropriado na fábrica, aguardando sua destinação. Sua construção foi sob uma fundação rasa, tipo radier, e possui $50 \mathrm{~m}^{2}$ de área construída onde foi distribuída em 1 (um) vestiário masculino, 1 (um) vestiário feminino, 1 (uma) sala de materiais mais 2 (duas) salas de uso geral e 1 (um) hall.

Foram 2 (dois) tipos de questionários de avaliação utilizados nesse trabalho, sendo um para o residencial construído pelo sistema "Jet Casa" e outro para o entorno da obra (bairro Itapajé) referente ao vestiário. Todos os questionários contêm perguntas mistas.

Ao total foram respondidos 75 questionários, sendo 49 para o residencial que utiliza o sistema "Jet Casa" e mais 26 questionários para o bairro Itapajé, local de construção do vestiário. Esses questionários foram aplicados através de visitação às residências dos moradores em horário comercial, normalmente no período da manhã: no residencial (sistema "Jet Casa") entre os dias 06 à 27 de janeiro de 2014 e no bairro Itapajé somente no dia 16 de janeiro de 2014.

\section{RESULTADOS}

As maiores patologias surgidas após a fabricação dos painéis são: a ocorrência de pequenas fissuras no reboco do entijolamento, pois os painéis são fabricados em uma superfície que não é totalmente regular ocorrendo seu desgaste e que não há como inspecionar durante a execução só podendo ser percebidas após o içamento das peças. A outra patologia que costuma ocorrer são as trincas em painéis grandes, normalmente em 
colunas e no reboco, assim como também as rachaduras do painel devido aos esforços ocasionados pelo içamento.

Diante disso os painéis utilizados para a construção do vestiário foram reprovados pelos seguintes motivos:

- Painel com esquadria invertida. (Figura 1)

- Painel com trincas profundas no reboco. (Figura 2)

- Painel com rachaduras na coluna de concreto da porta.

- Painel com falhas significativas no reboco do entijolamento.

- Painel com espessura do reboco do entijolamento incorreta.

- Painel fora de esquadro.

Figura 1 - Presença de algum tipo de fissura na residência

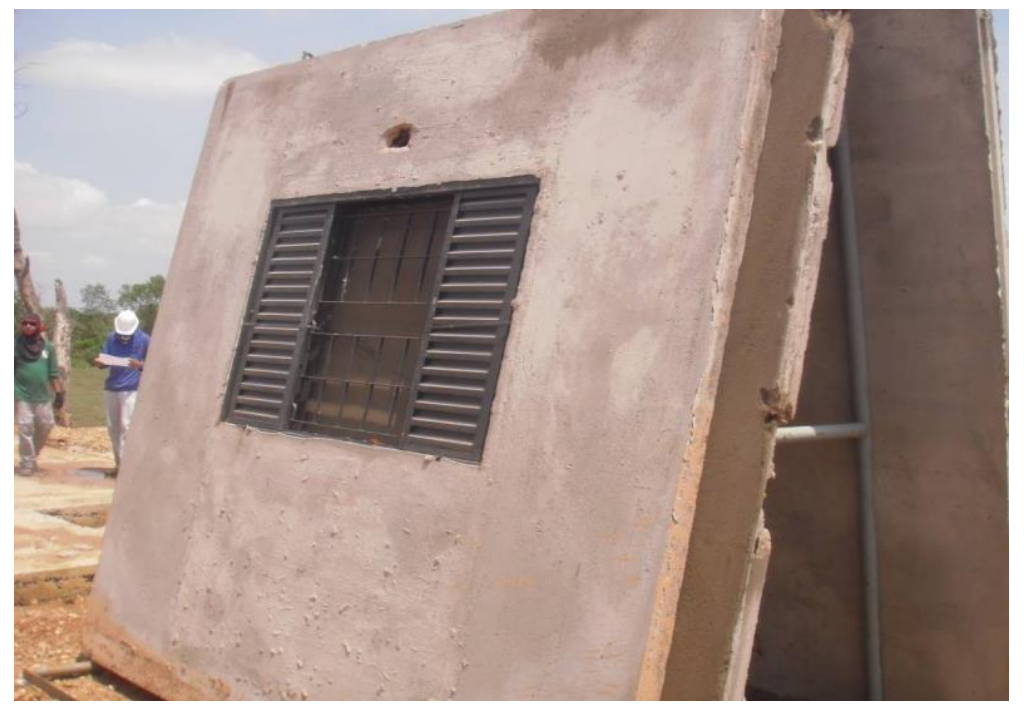

Figura 2 - Painel com trincas profundas no reboco

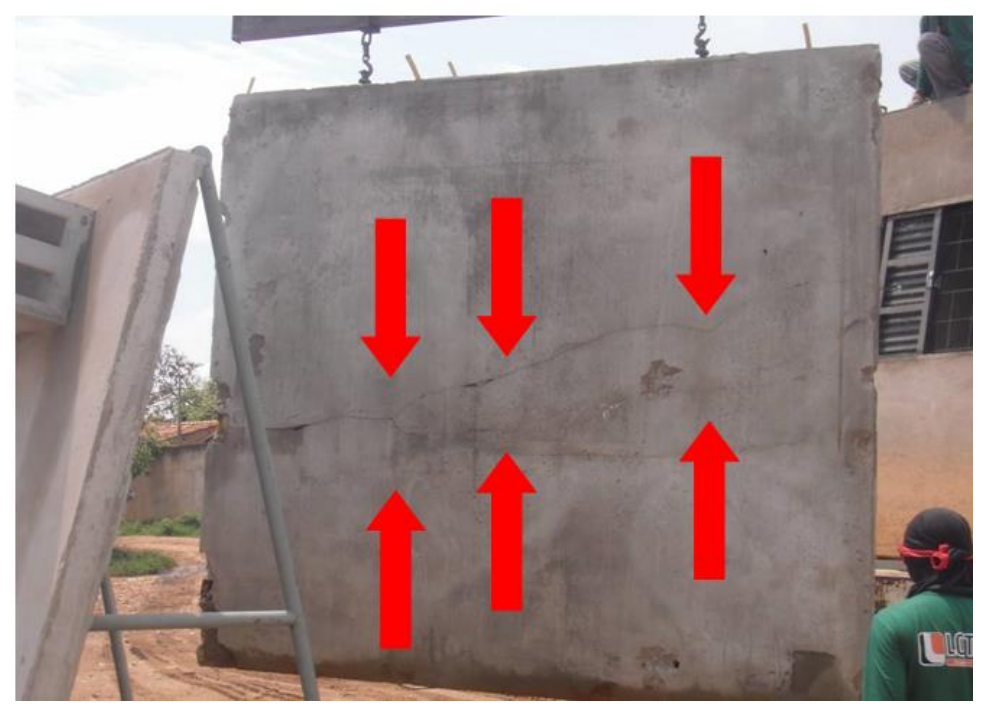


No que se refere aos resultados das pesquisas de satisfação, tanto no Residencial que utiliza o Sistema "Jet Casa" quanto no bairro Itapajé onde se localiza o vestiário, obtivemos a satisfação da maioria dos moradores.

Para o residencial (sistema "Jet Casa") foram preenchidos 49 questionários e tivemos um resultado de $70 \%$ das casas que não apresentaram nenhum tipo de fissura, trinca ou rachadura. E $86 \%$ das casas informaram não possuir nenhum tipo de infiltração. Esse mesmo percentual, $86 \%$ das casas, também não relataram nenhum problema para a perfuração e fixação nas paredes para a colocação de prateleiras, mobiliários, etc., exposto na Figura 3.

É importante salientar que $45 \%$ dos moradores que preencheram os questionários, não sabiam que suas casas foram construídas pelo sistema "Jet Casa', ou seja, de painéis de alvenaria pré-fabricados.

Já aos questionários aplicados ao bairro Itapajé, local de construção do vestiário, 77\% dos moradores já residem no bairro por mais de 10 anos e pensam que será bom para 0 bairro, em questão de valorização e infraestrutura, a construção do novo residencial ser próximo.

Ao que se refere a satisfação com a construção do vestiário de campo de futebol, $93 \%$ dos moradores ficaram muito satisfeitos com essa construção, pois proporcionará a população mais lazer, infraestrutura para a escolinha de futebol e integração com bairros vizinhos.

\section{CONSIDERAÇÕES FINAIS}

De acordo com toda a pesquisa observou-se que houve grande satisfação dos moradores do residencial, em relação ao imóvel, mostrando que o sistema construtivo "Jet Casa" apresenta poucos problemas com fissuras, infiltração e fixação nas paredes, onde prova o controle rigoroso no processo de fabricação e montagens dos painéis pré-fabricados.

Observou-se também que a satisfação atingiu a maioria no bairro Itapajé, onde foi construído o vestiário, pois a utilização dos painéis servirá como alternativa social e sustentável, pois o local carece de meios de lazer.

Ao final conclui-se que a sustentabilidade atingiu todas as dimensões como preconizou Silva e Shimbo (2006): pois nesse estudo notou-se que com a utilização desses painéis, reduziu-se o volume de descartes dos resíduos ao meio ambiente (dimensão Ambiental), realização do vestiário como alternativa de lazer a toda comunidade (dimensão Social), geração de trabalho e diminuição de gastos com compra de materiais (dimensão Econômica), consciência de reciclagem e meio ambiente (dimensão Cultural) e a construção de espaços que oportunizem a participação democrática da população (dimensão Política).

\section{REFERÊNCIAS}

ABRAMO, P. Formas de financiamento do acesso à terra e funcionamento do mercado fundiário-imobiliário: um ensaio com base na noção de regime urbano. IN: Cadernos IPPUR/UFRJ/ ano XII, n.1, (jan/jul 2002).

AGENDA HABITAT. União dos Movimentos Sociais de Moradia, 1997. 
CAIXA ECONÔMICA FEDERAL. Disponível em: http://www.caixa.gov.br. Acesso em: 20 de Setembro de 2013.

ASSOCIAÇÃO BRASILEIRA DE NORMAS TÉCNICAS. NBR 9062 - Projeto e execução de estruturas de concreto pré-moldado. São Paulo, 1985.

BONDUKI, N. G. Origens da Habitação Social no Brasil. Arquitetura moderna, Lei de Inquilinato e difusão da casa própria. São Paulo: Estação Liberdade, FAPESP, 1998.

BRASIL. Ministério das Cidades. Secretaria Nacional de Habitação: Déficit Habitacional no Brasil 2008. - Brasília, Ministério das Cidades, 2011, 140 p.

CAMARA. Disponível em: <http://www2.camara.gov.br>. Acesso em: 13 Ago. 2013 as $14 \mathrm{~h} 00 \mathrm{~min}$.

COELHO, W. R. - O Déficit das Moradias: Instrumento para Avaliação e Aplicação de Programas Habitacionais. Dissertação. 2002.

CONSELHO NACIONAL DO MEIO AMBIENTE - CONAMA. Resolução $\mathbf{n}^{\circ} \mathbf{3 0 7}$, de 05 de Julho de 2002. Gestão dos Resíduos da Construção Civil.

FARAH, M.F.S. Processo de trabalho na construção habitacional: tradição e mudança. São Paulo: Ed. AnnaBlume / FAPESP, 1996.

FERREIRA, J. S. W.; UEMURA, M. Política Urbana. In: Ministério das Cidades / Aliança de Cidades / DENALDI, Rosana (org.) Ações Integradas de Urbanização de assentamentos precários. Brasília: Ministério das Cidades, 2009.

GOVERNO DO ESTADO DE SÃO PAULO. Resíduos da Construção Civil e o Estado de São Paulo - A experiência do SindusCon-SP. São Paulo - SP, 2012. Disponível em: http://www.sindusconsp.com.br/downloads/prodserv/publicacoes/manual_residuos_solidos.pd f.

GUIA CBIC de Boas Práticas em Sustentabilidade na Indústria da Construção / Rafael Tello; Fabiana Batista Ribeiro. - Brasília: Câmara Brasileira da Indústria da Construção; Serviço Social da Indústria; Nova Lima: Fundação Dom Cabral, 2012.

HOWE, C. W. The management of fisheries: a case of renewable but destructible common property resources. In: Natural Resource Economics - Issues, analysis, and policy. New York, John Wiley \& Sons, 1979.

IPEA.

Disponível

em:

http://www.ipea.gov.br/portal/index.php?option=com_content $\&$ view=article\&id=20656

\&catid=1\&Itemid=7. Acesso em: 02/12/2013.

JET CASA. Disponível em: <http://www.jetcasa.com.br>. Acesso em: 13 Ago. 2013.

MARICATO, E. Habitação e Cidade. 7.ed. São Paulo: Atual, 1997.

PEPPE, C.R.A. \& BRANDT, C.S.P. Avaliação de um Sistema Construtivo Industrializado para Residência Unifamiliar. Trabalho de Conclusão de Curso. Fundação Educacional de Barretos, São Paulo, 2009.

PROGRAMA BRASILEIRO DA QUALIDADE NA PRODUÇÃO DE HABITAÇÃO PBQP-H. Sistema de Avaliação da Conformidade de Empresas de Serviços e Obras da Construção Civil - SIAC. Ministério das Cidades. Secretaria Nacional de Habitação. 2012.

REVISTA TÉCHNE (2005) Artigo: O que mudou na construção civil nos últimos dez anos? São Paulo. $\mathrm{N}^{\circ} 100$ - Julho, 2005.

SILVA, A. S.; SHIMBO, I. A dimensão política na conceituação da sustentabilidade. ENCONTRO NACIONAL DE TECNOLOGIA DO AMBIENTE CONSTRUÍDO. Anais. Florianópolis. 2006. 
SILVA, D. \& MORAES, I. Sustentabilidade (Reciclagem de Óleo Residual). TCC. SP, 2011.

SISTEMA NACIONAL DE AVALIAÇÕES TÉCNICAS - SINAT: Sistema Jet Casa de painéis pré-moldados mistos de concreto armado e blocos cerâmicos. Programa Brasileiro da Qualidade e Produtividade no Habitat - PBQP-H. Brasília, DF, 14 de novembro de 2011.

SUSTENTABILIDADE. Disponível em: http://www.atitutessustentaveis.com.br /sustentabilidade/. Acesso em 14/08/2013.

TRATADO DE EDUCAÇÃO AMBIENTAL PARA SOCIEDADES SUSTENTÁVEIS E RESPONSABILIDADE GLOBAL, 1992.

TRIGO, C.C. Pré-Fabricados em Argamassa Armada: Material, Técnica e Desenho de Componentes Desenvolvidos por Lelé, 2009. Dissertação (Mestrado) - Faculdade de Arquitetura, Universidade de São Paulo, São Paulo. 